Die Geschlechter im Gespräch 
Susanne Günthner / Helga Kotthoff

\title{
Die Geschlechter im Gespräch
}

\author{
Kommunikation in Institutionen
}

J.B. Metzlersche Verlagsbuchhandlung

Stuttgart 
Die Deutsche Bibliothek - CIP-Einheitsaufnahme

Die Geschlechter im Gespräch : Kommunikation in Institutionen / Susanne Günthner ; Helga Kotthoff. Stuttgart : Metzler, 1992

ISBN 978-3-476-00825-1

NE: Günthner, Susanne; Kotthoff, Helga

ISBN 978-3-476-00825-1

ISBN 978-3-476-03400-7 (eBook)

DOI 10.1007/978-3-476-03400-7

Dieses Werk einschließlich aller seiner Teile ist urheberrechtlich geschützt. Jede Verwertung außerhalb der engen Grenzen des Urheberrechtsgesetzes ist ohne $\mathrm{Zu}$ stimmung des Verlages unzulässig und strafbar. Das gilt insbesondere für Vervielfältigungen, Übersetzungen, Mikroverfilmungen und die Einspeicherung und Verarbeitung in elektronischen Systemen.

(C) 1992 Springer-Verlag GmbH Deutschland

Ursprünglich erschienen bei J.B. Metzlersche Verlagsbuchhandlung und Carl Ernst Poeschel Verlag GmbH in Stuttgart 1992 


\section{Inhaltsverzeichnis}

\section{EINLEITUNG}

Susanne Günthner / Helga Kotthoff

Vorwort

INTERAKTION IN DER SCHULE

Claudia Fuchs

Feministische Schulforschung

Ruth Groth

Der kleine Unterschied im Lachverhalten von Frauen und Männern und seine grossen Folgen. Eine linguistische

Untersuchung zum Interaktionsverhalten in der Schule

\section{INTERAKTIONEN IM HOCHSCHULBEREICH}

\section{Elisabeth Kuhn}

Geschlecht und Autorität. Wie Lehrende ihre

StudentInnen zur Mitarbeit bewegen

Claudia Schmidt

»Dieser Emil immer destruktiv«. Eine Untersuchung über weibliches und männliches Kommunikationsverhalten in studentischen Kleingruppen

\section{Susanne Günthner}

Die interaktive Konstruktion von Geschlechterrollen, kulturellen Identitäten und institutioneller Dominanz. Sprechstundengespräche zwischen Deutschen und Chinesen/innen

Helga Kotthoff Unruhe im Tabellenbild? Zur Interpretation weiblichen Sprechens in der Soziolinguistik 


\section{MEDIZINISCHER BEREICH}

Candace West

Ärztliche Anordnungen. Besuche bei Ärztinnen und Ärzten

Jennifer Hartog

Paare in der genetischen Beratung

\section{GERICHT UND PSYCHOTHERAPIE}

\section{Suzanne Schlyter}

Mann und Frau vor Gericht. Sprachverhalten während eines

Gleichberechtigungsprozesses

Robin Lakoff

Präsenz und Einfluß von Frauen in Institutionen. Kommunikative

Strategien und Stile vor Gericht und in der Therapiesituation

\section{FERNSEHDISKUSSIONEN}

\section{Helga Kotthoff}

Die konversationelle Konstruktion von Ungleichheit in

Fernsehgesprächen. Zur Produktion von kulturellem Geschlecht

\section{KOMMUNIKATION IM DEUTSCHEN BUNDESTAG}

\section{Armin Burkhardt}

»Das ist eine Frage des Intellekts, Frau Kollegin!«.

Zur Behandlung von Rednerinnen in deutschen Parlamenten

\section{SPRACHE IM KONTEXT DER KRIEGSMASCHINERIE}

Carol Cohn

Sexualität und Tod in der Sprache von Verteidigungsexperten 